\title{
Flower visiting Neuroptera: Mouthparts and feeding behaviour of Nemoptera sinuata (Nemopteridae)
}

\author{
Harald W. KRENN ${ }^{1}$, Barbara-Amina GEREBEN-KRENN ${ }^{1}$, Bernhardt M. STEINWENDER ${ }^{1}$ and Alexi POPOV ${ }^{2}$ \\ ${ }^{1}$ Department of Evolutionary Biology, University Vienna, Althanstrasse 14, 1090 Vienna, Austria; \\ e-mail: harald.krenn@univie.ac.at \\ ${ }^{2}$ National Museum of Natural History, Bulgarian Academy of Sciences, Tsar Osvoboditel Blvd 1, 1000 Sofia, Bulgaria
}

Key words. Mouthparts, flower-visiting behaviour, pollen, morphology, feeding, insects, Neuroptera, Nemopteridae

\begin{abstract}
The mouthparts of the spoon-winged lacewing Nemoptera sinuata are adapted for the uptake of pollen and nectar. Form and function of the mouthparts are described, and the technique of food uptake is discussed in context with flower-visiting behaviour and floral architecture of the preferred flowers. The maxillae are the main organs for food uptake. The brush-shaped laciniae, galeae and maxillary palpi form a functional unit which can be extended by the action of the cardo-stipes joint. Video analyses of the mouthpart movements distinguished different patterns of maxillary motions which occur in nectar feeding or pollen collecting. The flower-visiting behaviour and the specialised mouthparts of the Nemopteridae are derived traits which probably evolved from predatory and biting/chewing mouthparts within the Neuroptera.
\end{abstract}

\section{INTRODUCTION}

Adult Nemopteridae, the spoon-winged lacewings and the thread-winged lacewings, have an extraordinary appearance and are easily recognized by their ribbon or thread like hind wings which are much longer than the fore wings (Fig. 1). The larvae live in the soil and are predators of ants and other small insects; their daggershaped mouthparts are composed of the mandibles and maxillae; adults are flower-visitors and feed on nectar and pollen (Popov, 1963; Tjeder, 1967; Picker, 1987; Monserrat \& Martinez, 1995; Monserrat, 1996). Our knowledge of the feeding habits of adults is confirmed by analyses of the gut contents in a number of species from the two subfamilies of Nemopteridae, Crocinae and Nemopterinae (Popov, 1967, 1998; Tjeder, 1967, 1974; Monserrat, 1983, 1996), and by the analysis of excrements (Popov, 1973).

The great majority of insects with exclusively floral diets show adaptations of their mouthparts and feeding behaviour for the uptake of nectar and/or pollen (Krenn et al., 2005). Among the Neuroptera, the adults of some genera in various families (e.g. in Chrysopidae, Osmylidae, Sisyridae; rarely in Mantispidae, Berothidae and even in Hemerobiidae and Myrmeleontidae) have been observed to feed facultatively from flowers (e.g. Killington, 1936; Grinfeld, 1959; Popov, 1973; New, 1989; Aspöck \& Aspöck, 1999; Villenave et al., 2005), although their mouthparts belong to the biting/chewing functional type which is characterized by well developed biting mandibles (Aspöck \& Aspöck, 2003). The Nemopteridae include about 150 species (Aspöck \& Aspöck, 1999; Aspöck et al., 2001a) in Mediterranean, semiarid, arid and desert regions of southern Europe, southwest Asia, Australia, South America and Africa; the latter harbouring a particularly rich fauna in the Cape Region of
South Africa (Mansell, 1996; Monserrat, 1996). As far as known, adult nemopterids feed exclusively on pollen and nectar thereby taking advantage of their elongated heads and modified non-biting mouthparts (Tjeder, 1967; Popov, 1973). In adult nemopterids the mandibles are weak, and the maxillae and the labium are described to be more or less elongate, rod-like and setaceous, and to correspond to the length of the head (Tjeder, 1967; Hölzel, 1999). Although their regular flower visiting behaviour has been long known and the specialisations of the mouthparts have been described in several species (e.g. Tjeder, 1967), detailed studies of form, function, feeding technique and the evolution of feeding preferences have been neglected.

The members of the Palearctic genus Nemoptera are diurnal, flying in bright sunshine and are conspicuous flower visitors (Tjeder, 1967; Popov, 1971; Monserrat, 1996). The Balkan-Anatolian species Nemoptera sinuata is the only one in this genus for which observations of adult feeding behaviour exist (Popov, 1967, 2002). These lacewings harvest pollen from anthers by rapid movements of the mouthparts. In addition they collect pollen with the tarsi of the fore legs (Popov, 2002). The aim of the present study is to analyse the morphology of the mouthparts, as well as the details of their movements using video recordings, and to discuss feeding technique, flower-visiting behaviour and adaptations to floral diets in this species. The functional interpretation of the mouthparts of the Larger Balkan Spoon-winged Lacewing, Nemoptera sinuata, may serve as a model for the rather uniformly shaped mouthparts within Nemopteridae and could contribute to the understanding of the biology and life history of one of the most fascinating groups of Neuroptera. 


\section{MATERIAL AND METHODS}

\section{Morphology}

Adults of Nemoptera sinuata Olivier, 1811 (Neuroptera: Nemopteridae) were collected in spring 2005 in southwestern Bulgaria by A. Popov. They were fixed in $70 \%$ ethanol or in FAA solution, i.e. a mixture of $35 \%$ formalin, concentrated acetic acid, and $80 \%$ alcohol $(5: 1: 10)$.

Whole mount preparations of the mouthparts were made from dissected heads. They were soaked in diluted lactic acid at $40-50^{\circ} \mathrm{C}$ for $1-2$ days, washed in distilled water, and embedded on glass slides in polyvinyl lactophenol without dehydration. The preparations were covered with glass slips and dried at $50^{\circ} \mathrm{C}$.

Serial semithin-section technique was used to examine mouthpart anatomy with light microscopy and to reconstruct the functional mechanisms of movements. The isolated heads were dehydrated with acidified DMP (2,2-dimethoxypropane) and acetone, then embedded in ERL-4206 epoxy resin under vacuum impregnation (Pernstich et al., 2003). Semithin sections were cut using diamond knives and stained with a mixture of $1 \%$ azure II and $1 \%$ methylene blue in an aqueous $1 \%$ borax solution for approximately $1 \mathrm{~min}$ at $80^{\circ} \mathrm{C}$.
To view the heads with the scanning electron microscope (SEM), fixed samples were dehydrated in ethanol and submerged in hexamethyldisilazane prior to air drying (Bock, 1987). A graphite adhesive tape and silver paint were used to mount them on SEM viewing stubs. The samples were sputtercoated with gold and viewed in a Jeol JSM-35 CF scanning electron microscope. Digital photos were processed with Adobe Photoshop 6.

The mechanism of maxilla movements was studied in thawed specimens which were freeze killed. A cryo freeze aerosol spray (containing 1,1,1,2-tetraflouroethane) was used to shock freeze individuals during feeding. The shock-frozen individuals were put into deep cooled $100 \%$ ethanol at $-50^{\circ} \mathrm{C}$ for several days and were subsequently dehydrated at room temperature and then treated for SEM as described above.

\section{Field observation}

The flower-visiting behaviour of adult Nemoptera sinuata was studied in Struma Valley in southwestern Bulgaria on June 4-8, 2006. The study site was Kresnensko Hanche in Kresna Gorge; located at $41^{\circ} 46^{\prime} 49^{\prime \prime} \mathrm{N}$ and $23^{\circ} 09^{\prime} 21^{\prime \prime} \mathrm{E}$ at about $250 \mathrm{~m}$ above sea level. Observations of flower-visiting behaviour were conducted in an abandoned vineyard which at present is occasionally grazed by goats. The terraced area was situated

TABLE 1. Flowering plants of the study site (Kresna Gorge, Kresnensko Hanche, Bulgaria) that are potential food sources for Nemoptera sinuata (Neuroptera). Total number of flowers or inflorescences were estimated (mean relative frequency) in 9 plots of 6 $\times 1 \mathrm{~m}$ and numbers of feeding events. Predominant taxa in bold print.

\begin{tabular}{|c|c|c|c|}
\hline Flowering plants & $\begin{array}{c}\% \text { of total number } \\
\text { of flowers }\end{array}$ & $\begin{array}{c}\text { Number of observed feeding } \\
\text { events by } N \text {. sinuata }\end{array}$ & $\%$ of feeding events \\
\hline \multicolumn{4}{|l|}{ Caryophyllaceae } \\
\hline Silene dichotoma Ehrh. & $<1$ & 0 & 0 \\
\hline \multicolumn{4}{|l|}{ Ranunculaceae } \\
\hline Clematis vitalba $\mathrm{L}$. & $<1$ & 0 & 0 \\
\hline \multicolumn{4}{|l|}{ Brassicaceae } \\
\hline Sisymbrium loeselii L. & 2 & 0 & 0 \\
\hline Alyssum murale Waldst. et Kit. & 15 & 5 & 11 \\
\hline \multicolumn{4}{|l|}{ Rosaceae } \\
\hline Rubus caesius L. & 1 & 0 & 0 \\
\hline \multicolumn{4}{|l|}{ Fabaceae } \\
\hline Vicia villosa Roth & $<1$ & 0 & 0 \\
\hline \multicolumn{4}{|l|}{ Rhamnaceae } \\
\hline Paliurus spina-christi Miller & 1 & 0 & 0 \\
\hline \multicolumn{4}{|l|}{ Hypericaceae } \\
\hline Hypericum perforatum $\mathrm{L}$. & $<1$ & 0 & 0 \\
\hline \multicolumn{4}{|l|}{ Apiaceae } \\
\hline Caucalis platycarpos $\mathrm{L}$. & $<1$ & 0 & 0 \\
\hline Daucus guttatus Sibth. et Sm. & $<1$ & 0 & 0 \\
\hline \multicolumn{4}{|l|}{ Boraginaceae } \\
\hline Onosma aucherana DC. & 6 & 0 & 0 \\
\hline \multicolumn{4}{|l|}{ Lamiaceae } \\
\hline Salvia virgata Jacq. & 3 & 0 & 0 \\
\hline Acinos suaveolens (Sm.) G. Don fil. & $<1$ & 0 & 0 \\
\hline \multicolumn{4}{|l|}{ Dipsacaceae } \\
\hline Scabiosa triniifolia Friv. & $<1$ & 0 & 0 \\
\hline \multicolumn{4}{|l|}{ Campanulaceae } \\
\hline Campanula sparsa Friv. & $<1$ & 0 & 0 \\
\hline Legousia speculum-veneris (L.) Chaix & $<1$ & 0 & 0 \\
\hline Jasione heldreichii Boiss. et Orph. & $<1$ & 0 & 0 \\
\hline \multicolumn{4}{|l|}{ Asteraceae } \\
\hline Anthemis austriaca Jacq. & 17 & 2 & 5 \\
\hline Achillea millefolium $\mathrm{L}$. & $<1$ & 0 & 0 \\
\hline Achillea coarctata Poir. & 45 & 37 & 84 \\
\hline Carduus candicans Waldst. et Kit. & 6 & 0 & 0 \\
\hline
\end{tabular}



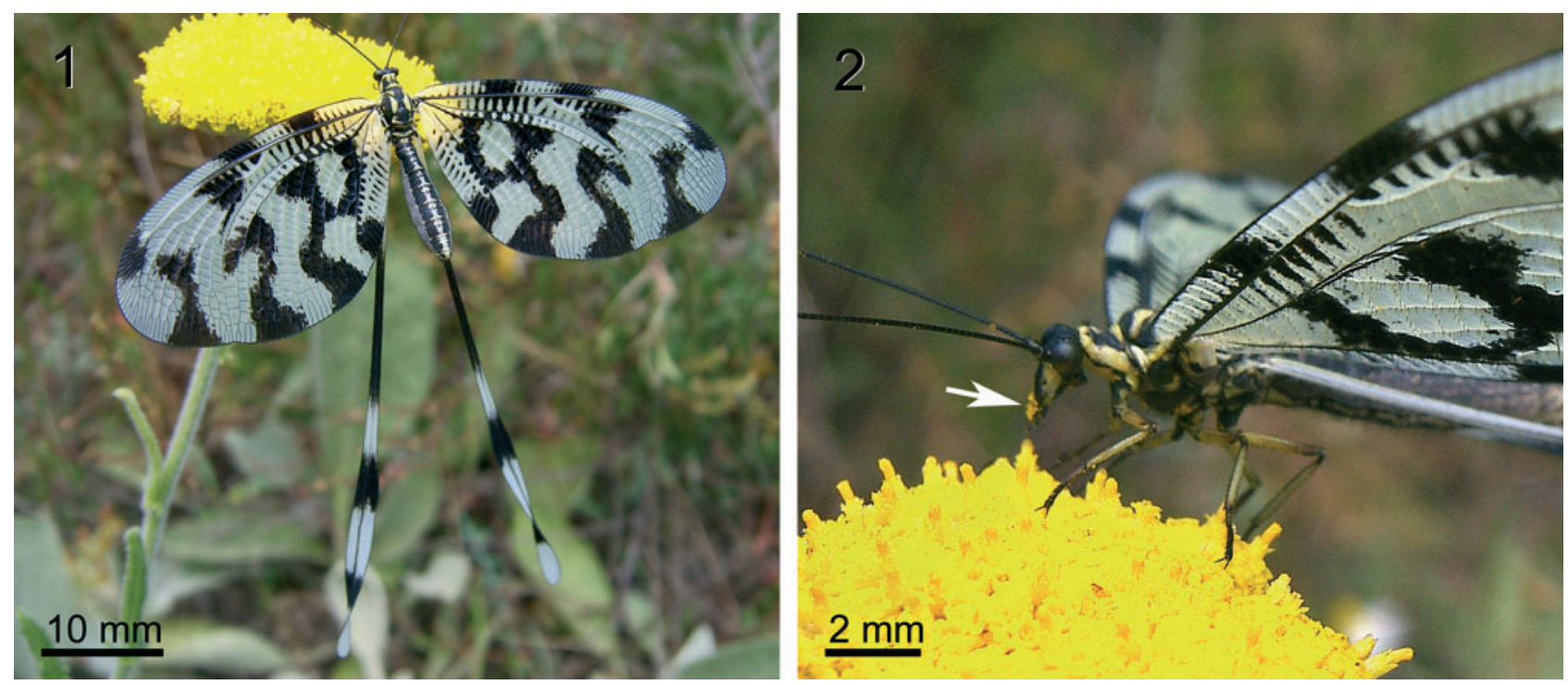

Figs 1-2. Nemoptera sinuata (Neuroptera: Nemopteridae). 1 - visiting a flower of Achillea coarctata (Asteraceae) (June 2006, Struma Valley, Bulgaria); 2 - feeding, accumulation of pollen on the frontal part of head; arrow. Inflorescence of Achillea coarctata composed of numerous single flowers.

between a gravel road and a slope under a rocky declivity. The study area can be characterized by a degraded Mediterranean vegetation with a plant cover of about $70-85 \%$ interspersed with pieces of granite blocks with a diameter up to $1 \mathrm{~m}$. The most frequent flowering plants are listed in Table 1. Grass and plant species that were not blooming were not identified since they are not important for the flower-visiting behaviour of Nemoptera sinuata in the study period. To estimate the mean relative frequency, all flowers in 9 plots of $6 \times 1 \mathrm{~m}$ were counted.

Photographs were taken with a Samsung V50 digital camera with a resolution of 5 million pixels. The flower-visiting behaviour was recorded using a Sony TRV 740E digital-8 camera with a close-up lens (Soligor V-37 MC) on a tripod allowing a scale of $2: 1$ at a distance of about $10 \mathrm{~cm}$. The videos contain one specimen feeding on Anthemis austriaca, one on Alyssum murale flowers and 10 specimens on the inflorescences of Achillea coarctata. The insects moved freely on the flowers. Digital videos of 12 individuals were taken, with a sum of 75 usable takes and a total time of $1.5 \mathrm{~h}$.

\section{Flowers of Achillea coarctata (Asteraceae)}

Since Achillea coarctata was the preferred flower of Nemoptera sinuata in the study area, the morphology of the inflorescences was studied in several individuals $(n=10)$ from the study area. The disc shaped secondary inflorescence (Fig. 1) is formed by several primary inflorescences which themselves consist of dense aggregations of tiny flowers (Simpson, 2006). Morphometry of the single flowers and the primary inflorescences was done using a stereomicroscope with an attached drawing tube. Longitudinally dissected florets were studied and measured to estimate the depth and location of pollen and nectar.

\section{RESULTS}

\section{Mouthpart morphology}

The head is snout-like, elongated into a rostrum formed by clypeus, labrum, mandibles, maxillae and labium (Figs $2,3)$. Frontally, the rostrum bears bristles with lengths of about $100 \mu \mathrm{m}$. The mouthparts assume the orthognathous position (Fig. 3). Although the length of the head is greater in females $(2.8 \pm 0.1 \mathrm{~mm}, \mathrm{n}=6)$ than in males $(2.5 \pm 0.2 \mathrm{~mm}, \mathrm{n}=6$, Mann Whitney U-test, $\mathrm{p}=0.015)$, the mouthparts of females and males are identical.

The labrum is convex in a transverse plane. It covers the mouthparts in their resting position (Figs 3, 6) and forms a preoral cavity beneath (Fig. 9). The proximal margin of the labrum is attached to the clypeus by a sinuate clypeolabral suture. The distal margin of the labrum is bifid with a median notch. The labrum can be raised to some extend by one pair of small muscles arising from the clypeus and inserting at the proximal margin of labrum (Fig. 9).

The pair of mandibles are hinged to the posterior-lateral margin of the head capsule (Figs 3,4). Each mandible is elongate, about $0.8 \mathrm{~mm}$ long and without dentation. Proximally the mandibles form the lateral sides of the preoral cavity. The distal half forms a frontally directed plate with thin and smooth inner margins located under the labrum (Fig. 12). This mandibular plate is strengthened by two longitudinal ridges. Their apical tip is directed in the median direction and bears a sensorial pit. Although no incisive region is discernible and a biting ability of the mandibles is improbable, large mandibular adductor and abductor muscles are present. They insert via long tendons at the mandible base and originate at the posterior head capsule (Fig. 11).

The paired maxillae are oriented in a longitudinal direction and form the most conspicuous structures of the mouthparts. The cardo is a convex plate that projects out from the posterior head at a right angle. The elongated stipes is twice as long as the cardo. Both structures are hinged to each other and the joint forms an angle of about $45^{\circ}$ in resting position (Fig. 3). A folded membranous cuticle connects the cardo-stipes joint laterally with the head and medially with the labium (Fig. 14). The distal part of the stipes forms a tube which bears the lacinia at the inner side and the galea and the maxillary palp at the 

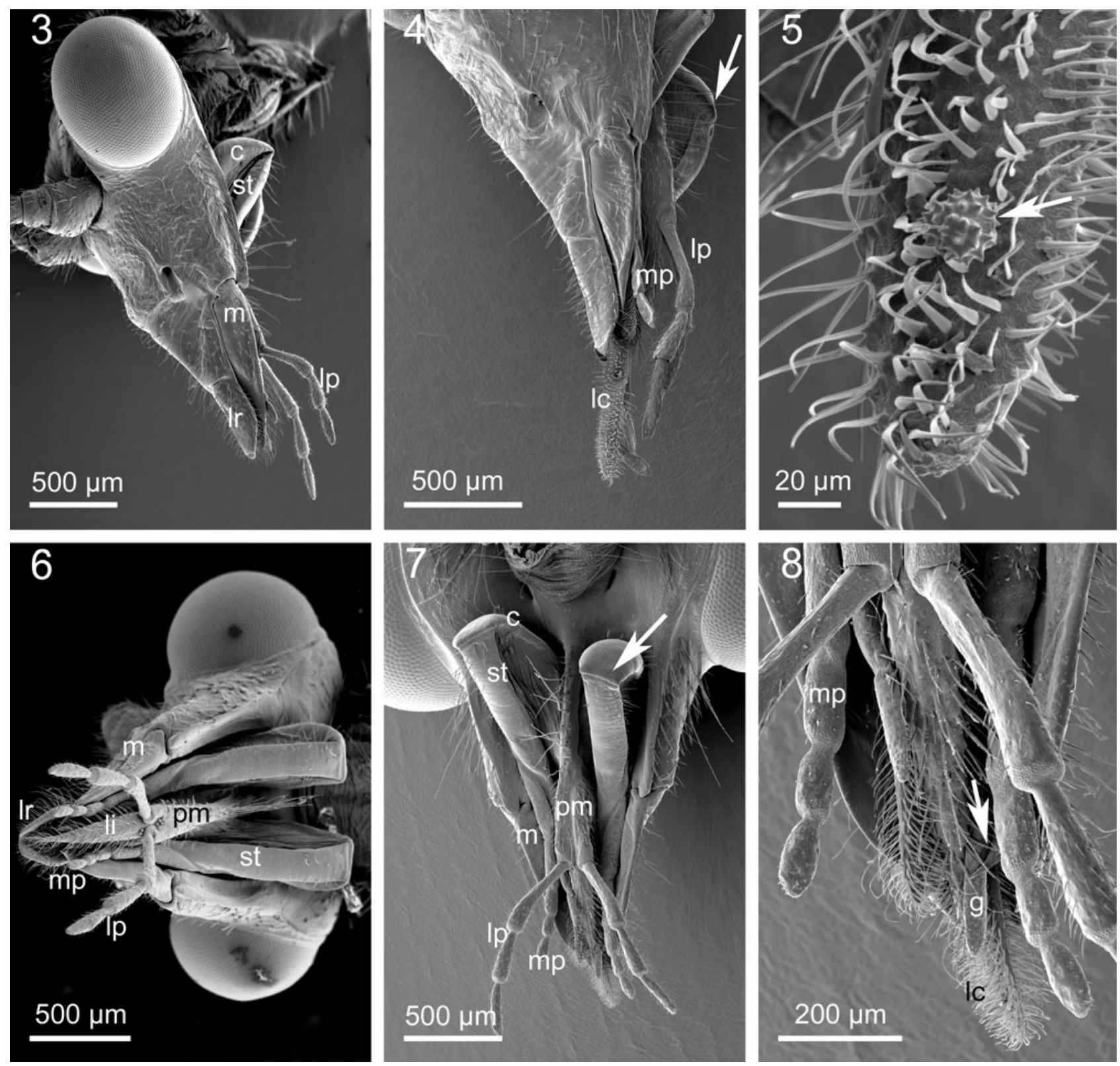

Figs 3-8. Head and mouthparts of Nemoptera sinuata (SEM micrographs). 3 - head in lateral view, mouthparts in resting position; $\mathrm{lr}$ - labrum, $\mathrm{m}$ - mandible, c - cardo, st - stipes, lp - labial palp. 4 - tip of the head and distal parts of right maxilla partly projected; cardo-stipes joint partly extended, arrow; lc - lacinia, $\mathrm{mp}$ - maxillary palp, lp - labial palp. 5 - median side of the lacinia with a pollen grain (arrow) sticking to the bristles; detail of Fig. 4. 6 - head in ventral view; maxillae in resting position; $1 \mathrm{r}-\mathrm{labrum}, \mathrm{m}-$ mandible, st - stipes, pm - prementum, li - ligula, mp - maxillary palp, lp - labial palp. 7 - posterior side of the head of a shockfrozen specimen; one maxilla partly projected; one cardo-stipes joint (arrow) partly extended; $\mathrm{m}$ - mandible, $\mathrm{c}-\mathrm{cardo}$, st - stipes, $\mathrm{mp}$ - maxillary palp, pm - prementum, lp - labial palp. 8 - magnification of Fig. 7; the brush-shaped lacinia (lc) of one body side partly projected; galea $(\mathrm{g})$ hooked into the apical point of the mandible (arrow); maxillary palps $(\mathrm{mp})$ bear sensilla.

lateral side. These distal maxillary parts are about $1 \mathrm{~mm}$ long and lie parallel to each other forming a set of rodlike structures under the mandibles (Figs 6, 7, 12). The maxillary base contains one pair of large muscles (Figs $10,11)$ which are labelled according to their origins and insertions. The musculus tentorio cardinalis originates at the posterior region of the tentorium and is attached to the whole length of the cardo. The second muscle, the musculus tentorio stipitalis, originates from the anterior region of the tentorium and extends to the stipes sclerite. The contraction of the musculus tentorio cardinalis obvi- ously extends the cardo-stipes joint and pushes the lacinia, galea and maxillary palp out of the labrum and mandible covering. The cardo-stipes joint and the lacinia are partly extended and visible in front of the head (Fig. 4). The musculus tentorio stipitalis is the antagonist to the cardinal flexor. It may retract the stipes and the distal maxillary parts and flex the cardo-stipes joint.

The lacinia is a flat rod densely covered with bristles (Figs 4, 5, 8). Their lengths range between 25 and $60 \mu \mathrm{m}$ (Fig. 5). They are curved and longer on the inner side and give the lacinia the appearance of a brush. The lacinia is 

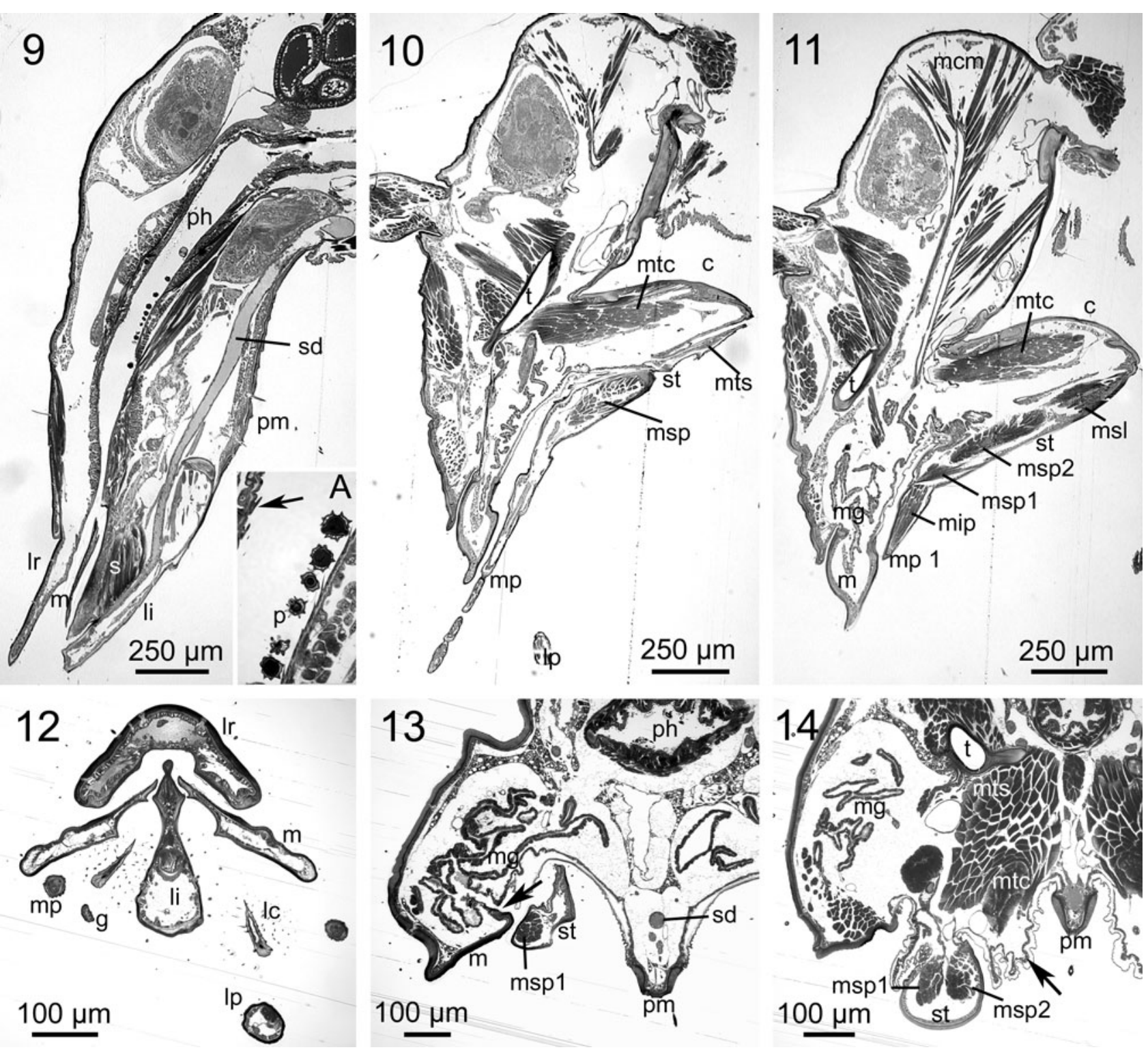

Figs 9-14. Semithin sections of the head and mouthparts of Nemoptera sinuata. 9 - head in sagittal section; labrum (lr) covers mandible (m) frontally. Salivary duct (sd) extends below the prementum (pm) of labium and opens through a muscular salivarium (s) at tip of the ligula (li). Pharynx (ph) contains pollen grains; inserted enlarged micrograph (A), arrow points to spine of pharynx, pollen grain (p). 10 - parasagittal section through the head; mouthparts flexed under the head in resting position; maxilla extension muscle (mtc musculus tentorio cardinalis) originate on the tentorium $(\mathrm{t})$, antagonistic maxilla retractor muscle (mts musculus tentorio stipitalis) only cut superficially; antagonistic muscles attached to the maxillary palp basis (msp); maxillary palp (mp) composed of five palpomers; c - cardo, st - stipes, lp - labial palp. 11 - Parasagittal section through the head; further lateral than in Fig. 10. Musculus tentorio cardinalis (mtc) inserts to the cardo (c); lateral side of the stipes (st) contains attachment points of the musculus stipito lacinalis (msl), external and internal musculus stipito palpalis (msp1, msp 2); the first segment of the maxillary palp (mp1) contains the musculus intrapalpalis (mip), mandible adductor originates at the head capsule (mcm musculus cranio mandibularis); sections through the mandibular gland $(\mathrm{mg})$ within the basis of the mandible $(\mathrm{m})$; t tentorium. 12 - cross-section through the tip of the head; labrum (lr) $\mathrm{u}$-shaped in cross section covers mandibles $(\mathrm{m}$ ) and ligula (li) frontally; laciniae (lc) below the mandibles; $\mathrm{g}-\mathrm{galea}, \mathrm{mp}$ - maxillary palp, lp - labial palp. 13 - cross-section through the head at the opening of the mandibular gland (mg); stipes (st) between mandible base $(\mathrm{m})$ and prementum $(\mathrm{pm})$ containing the salivary duct (sd). 14 - cross-section through the head; tubular stipes (st) contains a pair of muscles attached to the maxillary palp (msp1, msp2), stipes sclerite is connected via a folded flexible cuticle (arrow) with the prementum (pm) and the gena of the head capsule. Maxilla extension and retractor muscles (mtc, mts) originate on the tentorium $(\mathrm{t})$.

very thin in cross section (Fig. 12). A pair of muscles inserts at the base of the lacinia. The musculus cranio lacinalis originates from the head vertex and extends in a long tendon to the insertion at the inner corner of the lacinia sclerite. The second muscle, the musculus stipito lacinalis originates at the stipes sclerite and inserts at the ventro-lateral side of the lacinia base (Fig. 11).

The galea is slender and measures about $50 \mu \mathrm{m}$ in diameter (Fig. 12). It is subdivided into two parts by different sclerotization, but the parts do not form a joint and 

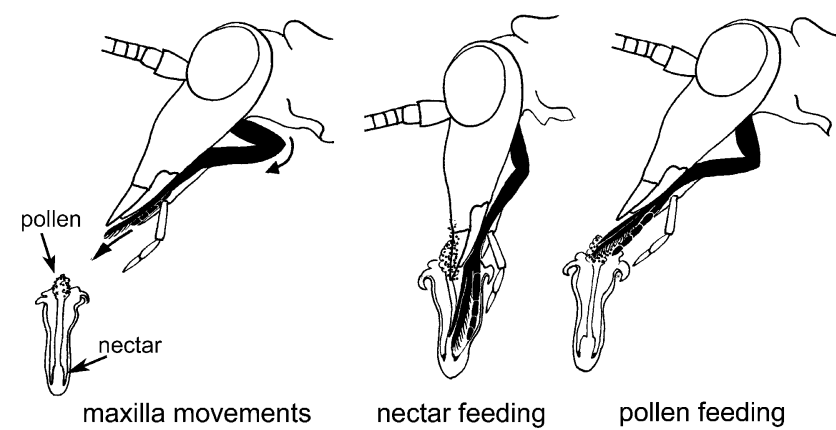

Fig. 15. Schematic drawing of the maxillary movements of Nemoptera sinuata during feeding from a single flower of Achillea; maxillae (in black) are pushed forward by extension of the basal maxillary joint (arrows). The lacinia, galea and maxillary palps are shown inserted into a flower during nectar feeding; ligula and labial palps remain outside; labrum and forehead are dusted with pollen. During pollen feeding the distal parts of the maxillae contact the pollen presented on the style.

the galea does not contain muscles. The galea arises next to the lacinia from the stipes; its distal part is hooked into the apical point of the mandible (Fig. 8). It bears one row of long bristles and the apex bears short sensilla basiconica.

The maxillary palp consists of 5 segments arranged in one row (Figs 6, 10) parallel to the galea and the lacinia. One pair of muscles (musculus stipito palpalis internus and $\mathrm{m}$. stipito-palpalis externus) originates from the stipes and is attached to the basal segment (Fig. 11). The first segment of the maxillary palp contains a single muscle while the other segments lack musculature (Fig. 10). The apical segment bears short cone-shaped sensilla basiconica and short bristle-shaped sensilla trichodea (Fig. 8).

The labium base surrounds the lower side of the occipital cavity of the head. It extends anteriorly into a slender rod-like structure lying between the maxillary bases (Figs 6, 7). This part, probably the mentum, is arched in cross section and bears two rows of long bristles. This sclerite is connected to the maxillae by folded membranous cuticle (Fig. 14) which allows the movements of the cardo-stipes joints. The prementum has a sclerotized lateral side and shows a medial groove. It bears the pair of 3-segmented labial palps and the median ligula (Figs 6, 7). Labial palps are the only distal structures that can be seen laterally in the resting position of the mouthparts (Fig. 3). They bear small cone-shaped sensilla basiconica and short bristle-shaped sensilla trichodea apically. The prementum sclerite gives rise to a pair of small muscles (musculus praemento palpalis) which are attached to the base of the palps. The median structure of the labium, the ligula, is pointed and bears numerous curved bristles 50-100 $\mu \mathrm{m}$ long. The ligula does not contain muscles.

A conspicuous salivary canal extends in the sagittal plane through the head under the labium sclerite (Fig. 9). It opens at the ligula into the preoral cavity. A salivarium is formed by muscles derived from the hypopharynx (Fig. 9).

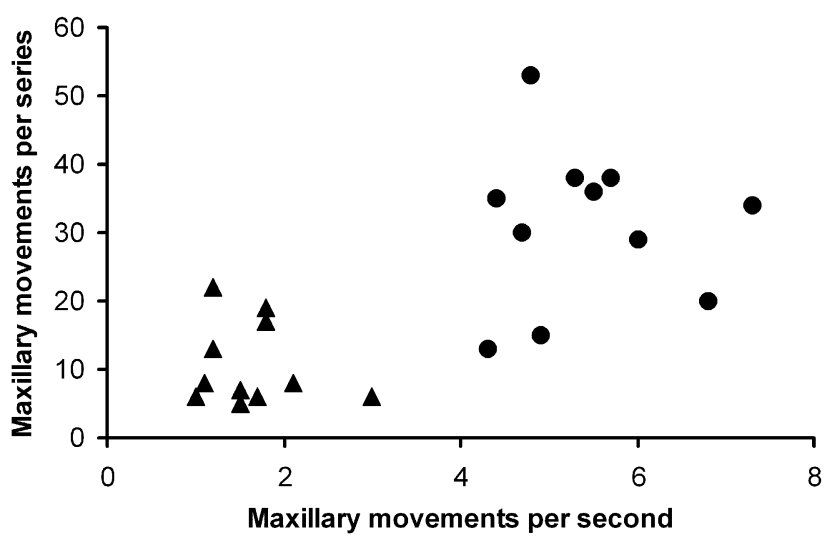

Fig. 16. Pattern of maxillary movements during feeding of Nemoptera sinuata from inflorescences of Achillea coarctata (Asteraceae). Nectar feeding is characterized by short series of maxillary movements in low frequency (movements per second) and pollen feeding by long series of maxillary movements at a higher frequency (movements per second). Maxillary movements per second in nectar feeding and pollen feeding are significantly different (Mann Whitney U-test, $\mathrm{N}=22, \mathrm{p}<0.001$ ); $\Delta$ - nectar feeding, $\bullet-$ pollen feeding.

The head of Nemoptera sinuata contains a very large pair of mandibular glands. It consists of convoluted tubes which extend from the epidermis under the membranous cuticle between the maxillae and the labium into the bases of the mandibles (Figs 11, 13). The opening lies between the base of the mandible and the distal part of the maxilla. A substance can be seen inside the tubes in the cross section (Fig. 13). The wall of the tubular glands is continuous with the epidermis and consists of high prismatic gland cells. A short duct opens from outside under the distal part of stipes (Fig. 13).

The wall of the pharynx is formed by circular muscles. Its inner surface is covered with small spines (about 10 $\mu \mathrm{m}$ long) which are directed in a proximal direction (Fig. 9A). In consideration of this anatomical arrangement it can be concluded that muscular contractions compress the tubular pharynx and thereby the spines transport the pollen grains further into the alimentary tract.

\section{Flower-visiting behaviour}

Nemoptera sinuata was active only during sunshine at temperatures above $17^{\circ} \mathrm{C}$ with little or no wind. In the study area the flower-visits were restricted to yellow or yellow-white inflorescences (Fig. 1). Within two days, feeding behaviour could be observed 37 times on inflorescences of Achillea coarctata (Asteraceae), five times on Alyssum murale (Brassicaceae) and twice on Anthemis austriaca (Asteraceae) (Table 1). Other blooming flowers were not visited. The comparison to the overall occurrence of blooming plants showed that Nemoptera sinuata prefers the dense umbrella shaped secondary inflorescences of Achillea coarctata for food uptake in the study area. The estimated numbers of blooming plants and the flowers actually visited in the study area are given in Table 1. The pollen grains of a blooming floret of Achillea coarctata stick to the style of the flower (Fig. 2), in addition the style projects above the surface of the 
inflorescence which has a diameter of $2-4 \mathrm{~cm}$. The pollen is thus readily available from above. The single flowers form small yellow 5-lobed tubular corollas. These florets consist of a short corollar tube with a depth of $1.36 \pm 0.17$ $\mathrm{mm}(\mathrm{n}=10)$. The opening is oval with a diameter of $0.4 \pm$ $0.05 \times 0.3 \pm 0.04 \mathrm{~mm}(\mathrm{n}=10)$.

Feeding behaviour starts with a search for the appropriate single flower. The insect walks over the inflorescences and turning movements of the body are observable. Nemoptera sinuata searches for a suitable single flower in a systematic manner and rarely returns to the same area a second time. Mouthpart movements are restricted to shaking motions of the labial palps which are observable occasionally.

Suitable florets are probably recognised by the pollen mass which they present on the style. Nemoptera sinuata stands in front of a chosen floret and inserts the head rostrum into the corolla. At the same time the basal maxillar joints are extended and the distal parts pushed deep into the corolla (Fig. 15). The extension movements of the cardo-stipes joints indicate that the distal parts of maxillae are inserted as far as possible. In some cases the head is also bent at the neck for deeper insertion. The cardostipes joints are extended and flexed 1-3 times per second in a series of approximately 5-22 movements (Fig. 16). Labial palps remain outside the corolla. Mandible movements are not visible.

In most observed events, the insertion of mouthparts is followed by feeding of the pollen mass on the floral style. When Nemoptera sinuata raises its head, the mouthparts contact the pollen. Movements of the cardo-stipes joints partly extend the distal parts of maxillae. The tips of the maxillary structures become visible in front of the head, and they tear off pollen grains (Fig. 15). Retraction movements caused by flexion of the basal joint seem to transport pollen under the labrum and between the mandibles. The labrum is sometimes slightly raised, however mandible movements are not discernible. Labial palps are also moved occasionally. Normally the laciniae are extended synchronously with galeae and maxillary palps, and together they function as a unit. At times, the distal parts of maxillae shift toward each other. The frequency of extension and flexion of the basal joints was 4.3-7.3 movements per second in long series of 13-52 successive movements (Fig. 16). Nemoptera sinuata feeds by first removing the pollen available on the styles immediately next to itself, then it turns to continue feeding from the styles further away.

The comparison of the feeding movements clearly shows different patterns. There are short series of distinct movements of the cardo-stipes joint in low frequency when the rostrum is inserted into the corolla. A second pattern of movements occurs when the insect feeds from the pollen grains outside the corolla. This type of movements is characterised by long series of shallow joint movements in higher frequency. The analysis of movement frequencies indicates significant differences (Mann Whitney U-test, $\mathrm{N}=22, \mathrm{p}<0.001$ ) (Fig. 16).
In some cases, pollen accumulates on the frontal side of the head when Nemoptera sinuata inserted its rostrum into a floret (Figs 2, 15). Cleaning behaviour of the fore legs could be observed as part of the feeding behaviour. If pollen accumulates on the fore tarsi during the searching behaviour, it is cleaned by drawing one leg at a time through the extended mouthparts. Slight extension movements of distal parts of the maxilla could be observed. This behaviour was described as nibbling the tarsi of the fore legs. In a few cases we observed that the fore tarsi were wiped over the head, the attached pollen grains were removed and taken up by the mouthparts.

\section{DISCUSSION}

\section{Functional anatomy of the mouthparts}

The adults of Nemopteridae have been observed in southern Europe and South Africa to be regular flower visitors feeding floral diets (Picker, 1984; Monserrat, 1985; Picker \& Leon, 1990; Popov, 1998). Pollenophagy of adults was observed for the first time by Popov (1967) in the Larger Balkan Spoon-winged Lacewing, Nemoptera sinuata. The structures of the mouthparts suggested that it feeds only on pollen; this interpretation could be confirmed by field observations and gut analyses (Tjeder, 1967; Picker, 1987; Mansell, 1992, 1996; Monserrat, 1996; Popov, 2002). The results of the present study indicate that nectar is also consumed.

The various mouthpart components of Nemoptera sinuata have their particular functional roles in the uptake of floral diets. The maxillae are the main organs of food uptake. The movements of the basal cardo-stipes articulation protracts and retracts the distal maxillary structures. The brush-shaped setaceous laciniae function as a pollen collecting organ and probably also take up nectar between the hairs through capillary action. The rod-like galeae are interpreted to function as a guiding structure for the lacinia since each galea slides over the hook-shaped apical tip of the respective mandible. The maxillary palps which are likewise inserted into the flower along with the other maxillary structures probably function as sensory organs since sensilla could be recognized only on these structures. The sensilla at their tips could provide information on conditions from inside the corolla. The labium is immovable, except for the palps. The salivary duct opens under the apical ligula, a hairy organ which serves to distribute saliva. The labial palps remain outside the flowers and bear sensilla at the tips that probably help to detect appropriate florets on the inflorescence.

The brush-shaped laciniae collect pollen grains and may also take up nectar by adhesion. According to our interpretation, after retraction of the pollen loaded laciniae under the labrum, the mandibles close so that their inner margins remove the pollen from the laciniae and move it to the median side. In this way these structures help to transport it toward the mouth. A simple transport mechanism for pollen was discovered in the pharynx, namely the numerous retrorse spines which line the compressible pharynx. Salivary fluid may also be vital functioning for internal transport of pollen. The secretions of 
the mandibular glands that open under the maxillae presumably also function to moisten the laciniae enabling the adherence of pollen to the hairs.

Comparison to illustrations and descriptions of mouthparts in other Nemopteridae (Tjeder, 1967) indicates the same composition and suggests similar functional mechanisms. The Crocinae are characterised by extremely elongated heads and correspondingly long maxillae. The rostrum is longest in Thysanocroce, Tjederia, Laurhervasia, Amerocroce, Moranida, Anacroce, Afghanocroce and some Dielocroce (Tjeder, 1967; Hölzel, 1975; Mansell, 1977, 1980, 1983). At least in some representatives of this subfamily the galea is much longer than the lacinia and the maxillary palps. It can be extended like a telescope out of a tubular structure which is formed by the so called palpifer, i.e. the distal portion of the stipes which bears the maxillary palp (Tjeder, 1958, 1967). On the contrary, in Derhynchia (Nemopterinae) the rostrum is completely lacking, the mouthparts are highly reduced and lacinia, galea and ligula are absent. However, even in this case the only known species, D. vansoni Tjeder, 1967 , is a pollen-eater (Tjeder, 1967).

Tjeder (1967) regarded the maxillary palp to consist usually of four segments originating from a large immovable palpifer. The present anatomical results show a muscle inside this structure which asks for anatomical interpretation in Nemoptera sinuata. Since the basal segment of the maxillary palp is recognised by a muscle (Snodgrass, 1935; Weber, 1933), the basal most part of the maxillary palp in Nemoptera sinuata should be considered as the first segment of the maxillary palp which is more or less fused with the stipes. Therefore we consider the maxillary palp to be 5-segmented.

\section{Flower morphology and feeding behaviour}

The inflorescence (i.e. dense cluster of small flowers called florets) of the preferred host plant Achillea coarctata consists of several so-called capitulae arranged in a disc shaped secondary inflorescence (Simpson, 2006). The morphometric results indicate that the florets correspond in size and shape with the head and mouthparts of Nemoptera sinuata. The florets are protandrous from the margin to the centre of the inflorescence. The anthers are united cylindrically forming a tube around the style. The style grows through them and pushes pollen out of the anthers and thus presents an agglomeration of pollen attached to the style above the surface of the inflorescence. This means that pollen is freely available in a protandrous floret and can be harvested by the insect from above (Fig. 15). When feeding on pollen, the insects raise the labrum, and by means of small movements of the distal maxillary structures the pollen grains are rubbed off the style. Maxillar movements are of a relatively high frequency, they persist for a considerable period of time (Fig. 16) and do not show great extensions of the cardostipes joint.

Based on flower morphology of Achillea coarctata and the feeding behaviour of Nemoptera sinuata it is evident that not only pollen is ingested when the head is pushed into a flower. Nectaries are present at the apex of the ovary (Simpson, 2006) on the bottom of the corolla which measures about $1.36 \mathrm{~mm}$. It seems reasonable to assume that Nemoptera sinuata is able to take up nectar using the laciniae since the maxillary structures can be projected at least $1 \mathrm{~mm}$. Video analyses of mouthpart movements show a particular pattern of maxilla movements when the head is pushed into the corolla tube (Fig. 16). The maxillary movements are of low frequency and the stipes-cardo joint is extended completely suggesting that this movement is used for taking up nectar from the bottom. The setaceous lacinia could serve as a sponge-like structure that soaks up nectar which would be transported to the mouth after retraction. The videos of this flower-visiting behaviour demonstrate that pollen is attached to the clypeus after the head separates from a flower (Fig. 15).

In some cases it could be observed that the insect cleans its fore legs by dragging the tarsi through the opened mandibles and raised labrum. Similar observations were recorded by Popov $(1967,2002)$ for Nemoptera sinuata and by Monserrat (1985) for Nemoptera bipennis (Illiger, 1812). Pollen removed from the legs in this manner is apparently ingested. Tjeder $(1967,1974)$ found in most genera of Nemopteridae large numbers of densely situated small setae covering an area on the ventral and inner apical surface of fore tibia. He observed pollen grains among these setae in Nemoptera and interpreted them as pollen-collecting hairs. However our examination of the fore tibia in Nemoptera sinuata failed to confirm the presence of any special structures.

The main diet of Nemopteridae is most likely pollen; this has been shown to be the case for Palmipenna aeoleoptera Picker, 1987 (Picker, 1984, 1987), Nemoptera bipennis (Monserrat, 1985, 1996) and many other species (Tjeder, 1967). Nemoptera sinuata has been recorded to visit primarily the flowers of Achillea coarctata, Alyssum murale and Hypericum rumeliacum (Popov, 1967, 2002). A preference for the first two species was confirmed in the present study but these insects also feed from flowers of another species of Asteraceae, namely Anthemis austri$a c a$, and to a minor extent visit flowers from other plant families. A comparison of the frequency of flowers in the study site reveals that Nemoptera sinuata utilized the most frequent flowers in the area for feeding. The comparison however suggests that inflorescences of a certain floral architecture are preferred. The latter is readily understandable because Nemoptera sinuata is not an agile flier and requires a platform for landing. The flower architecture of the visited Asteraceae (Achillea, Anthemis) has the advantage that pollen is easily harvested and the corollae are not longer than approximately $1 \mathrm{~mm}$.

Feeding observations and identification of the pollen in gut content of Nemoptera bipennis indicate that a wide spectrum of plants are utilized (Monserrat, 1996) belonging to the families Asteraceae (Bellis, Carduus, Helianthus, Taraxacum, Andryala), Campanulaceae (Jasione, Campanula), Caryophyllaceae (Silene), Lamiaceae (Lavandula, Thymus), Fabaceae (Sarothamnus), Apiaceae (Tapsia), Brassicaceae, Poaceae, as well as conifers. It would be interesting to observe the feeding 
behaviour in flowers of Campanulaceae and other families, which differ in shape from Achillea coarctata. The long heads and the partly tubular mouthparts of the Crocinae (Tjeder, 1967) suggest an adaptation to tubular flowers and the uptake of nectar as well. In particular, some Crocinae have extremely long heads and their maxillae are correspondingly long (Hölzel, 1975; New, 1989). This correspondence suggests a special adaptation to long tubular flowers, however details on their feeding preferences are lacking.

The phenological data for most Nemopteridae show a relatively short period of adult occurrence. The emerging of some species is synchronised to coincide with the ephemeral flush of spring flowers in semiarid regions (Mansell, 1996). Even if there are plenty of blossoming plants in the Mediterranean area, the spring period of flight of Nemoptera sinuata is an adaptation for life in habitats in which the vegetation develops in early spring (Popov, 2007). The same was observed by Monserrat (1983) even if the adults live in extremely dry habitats with sparse vegetation, as it is the case of Pterocroce capillaris (Klug, 1836). However, some species in South Africa emerge several month after spring when there are no spring flowers. This seasonal pattern of adult activity is genus-specific (Tjeder, 1967).

\section{Evolution of flower-visiting behaviour in Neuroptera}

The monophyly of the Neuroptera has never been doubted and is mainly based on the specialized sucking mouthparts of the larvae (Aspöck, 2002). In the phylogenetic system of Withycombe (1925) based on larval morphology, the Nemopteridae were included in the superfamily Myrmeleontoidea and were considered as sister group to the remaining families: Nymphidae, Myrmeleontidae and Ascalaphidae. Tillyard (1926) raised the nemopterids to a distinct superfamily, Nemopteroidea, and listed it before Myrmeleontoidea. Half a century later, Popov (1973) reversed the arrangement and regarded the Nemopteroidea as more specialised than the Myrmeleontoidea. According to current opinions, the Neuroptera consist of three monophyletic groups (suborders): Nevrorthiformia, Hemerobiiformia and Myrmeleontiformia (Aspöck, 1992). Mansell (1992) placed the Nemopteridae in the Myrmeleontoidea. In his cladogram the Nemopteridae are the sister group to Nymphidae + (Myrmeleontidae + Ascalaphidae) and the Psychopsidae formed the sister group to all other families in the superfamily. In a recent morphological cladistic analysis (Aspöck et al., 2001b), the Nemopteridae were considered to belong to Myrmeleontiformia on the basis of hindwing venation. Furthermore, the Nemopteridae formed the sister group to Psychopsidae and both families were considered the sister group to Nymphidae + (Myrmeleontidae + Ascalaphidae) . However, the position of Nemopteridae was not corroborated in a study using molecular data where Nemopteridae turned out to be the sister group to Myrmeleontidae + Ascalaphidae (Haring \& Aspöck, 2004).

Of the two subfamilies of Nemopteridae, the Nemopterinae were treated by Tjeder (1967) as the more advanced, but Mansell (1986) listed five autapomorphies in Crocinae, and showed thereby that the Nemopteridae are more ancestral. The monophyly of Nemopteridae was well determined on the basis of larval and adult characters, thus Monserrat's (1996) proposal for a polyphyletic origin of the family and a placement of the two subfamilies in different suborders (Hemerobiiformia and Myrmeleontiformia) does not find support (Aspöck et al., 2001a).

The adult mouthparts of Neuroptera belong to the biting/chewing functional type (New, 1989; Aspöck \& Aspöck, 1999). The modifications in adult mouthparts of Nemopteridae are derived from this biting/chewing functional type. The elongated head and correspondingly long mouthparts seem to be an autapomorphy of Nemopteridae. However, the mandibles have lost their biting function probably to help removing pollen from other mouthpart structures; the maxillae are extensible and function as pollen and nectar collectors; the labium has evolved into an organ which distributes saliva. The lengths of heads and maxillae are interpreted as adaptations to various flower corolla lengths.

Pollen feeding insects must cope with the task of gathering a more or less sticky powder available only in tiny quantities in flowers. Various modes of pollen feeding techniques exist and correspond to the mouthpart morphology (Krenn et al., 2005). Characteristic mouthpart modifications to pollen feeding are hairy structures on moveable parts where saliva seems to be crucial for pollen adhesion. Many of the pollen feeding insects also feed on nectar as suggested for Nemoptera sinuata according to the present data. In Coleoptera, for example, pollen and nectar are collected by sweeping movements of the moistened setaceous mouthparts (Fuchs, 1974; Johnson \& Nicolson, 2001; Karolyi, 2007). In Diptera nectar and pollen are suspended in saliva on the labellar surface prior to suction. The extent to which mouthparts are involved in primary pollen collection varies in different insects. In many bees, beetles and some flies pollen adheres first to body hairs, then it is collected by grooming behaviour with their legs and is subsequently cleaned in a second step using the mouthparts. A similar behaviour was also found in Nemoptera sinuata (Popov, 2002; present study). The various techniques of harvesting pollen suggest multiple evolutionary origins from different modes of feeding in adult insects. Krenn et al. (2005) listed carnivorous, spore-feeding, nectar-feeding, generalised phytophagous or petal-feeding behaviour as potential plesiomorphic feeding preferences which have led to pollen-feeding. In Neuroptera carnivory seems to be the plesiomorphic feeding mode. The flower visiting behaviour and specialised mouthparts of adult Nemopteridae are autapomorphic and are interpreted to be adaptations to pollen and nectar feeding. The present functional analysis of the feeding behaviour in Nemoptera sinuata can be used as a model for other nemopterids. In particular, the biology of members of Crocinae is not well studied and there are only few observations of the feeding behaviour of these nocturnal insects. The remarkably long mouthparts of some species (Tjeder, 1967; Hölzel, 1999), 
comprising tubular structures which suggest telescopic movements of the galea, probably indicate the existence of particular specializations for nectar feeding from long floral spurs and should stimulate further investigation of the biology of these amazing insects.

ACKNOWLEDGEMENTS. We are indebted to E. Zellinger for the preparation of the semithin sections and to U. Aspöck for literature and for access to the collection of the Museum of Natural History in Vienna. We would like to thank J. Plant for linguistic help, and D. Dimitrov for identification or confirmation of the flowering plant species.

\section{REFERENCES}

Aspöck H., Hölzel H. \& Aspöck U. 2001a: Kommentierter Katalog der Neuropterida (Insecta: Raphidioptera, Megaloptera, Neuroptera) der Westpaläarktis. Denisia 2: 606 pp.

AspöcK U. 1992: Crucial points in the phylogeny of the Neuroptera (Insecta). In Canard M., Aspöck H. \& Mansell M. (eds): Current Research in Neuropterology. SACCO, Toulouse, pp. 63-73.

AsPöcK U. 2002: Phylogeny of the Neuropterida (Insecta: Holometabola). Zool. Scripta 31: 51-55.

Aspöck U. \& Aspöck H. 1999: Kamelhälse, Schlammfliegen, Ameisenlöwen... Wer sind sie? (Insecta: Neuropterida: Raphidioptera, Megaloptera, Neuroptera). Stapfia 60: 1-34.

AsPöCK U. \& AsPÖCK H. 2003: 30. Ordnung Neuroptera (Planipennia), Netzflügler. In Dathe H. (ed.): Lehrbuch der Speziellen Zoologie. Band I: Wirbellose Tiere. 5. Teil: Insecta. Spektrum Akademischer Verlag, Heidelberg, Berlin, pp. 564-584, 890-892.

Aspöck U., Plant J.D. \& NemeschKal H.L. 2001b: Cladistic analysis of Neuroptera and their systematic position within Neuropterida (Insecta: Holometabola: Neuropterida: Neuroptera). Syst. Entomol. 26: 73-86.

Bock C. 1987: A quick and simple method for preparing soft insect tissues for scanning electron microscopy using Carnoy and Hexamethyldisilazane. Beitr. Elektronenmikr. Direktabb. Oberflächen 20: 209-214.

GRINFELD E. 1959: Feeding of adult lacewings (Neuroptera) with pollen and their probable role in origin of entomophily in plants. Vest. Leningrad. Univ. 14(9): 48-55 [in Russian].

Fuchs G.-V. 1974: Die Gewinnung von Pollen und Nektar bei Käfern. Natur Mus. 104(2): 45-54.

HARING E. \& AsPÖCK U. 2004: Phylogeny of the Neuropterida: a first molecular approach. Syst. Entomol. 29: 415-430.

Hölzel H. 1975: Revision der Netzflügler-Unterfamilie Crocinae (Neuroptera: Nemopteridae). Entomol. Germ. 2: 44-97.

Hölzel H. 1999: Die Nemopteriden (Fadenhafte) Arabiens. Stapfia 60: 129-146.

Johnson S.A. \& Nicolson S.W. 2001: Pollen digestion by flower-feeding Scarabaeidae: protea beetles (Cetoniini) and monkey beetles (Hopliini). J. Insect Physiol. 47: 725-733.

Karolyi F. 2007: Die Mundwerkzeuge des Blüten besuchenden Rosenkäfers Cetonia aurata (L.) (Coleoptera: Scarabaeidae). Diploma thesis, University of Vienna, $90 \mathrm{pp}$.

Killington F.J. 1936: A Monograph of the British Neuroptera. Vol. 1. The Ray Society, London, $\mathrm{xx}+269 \mathrm{pp}$.

Krenn H.W., Plant J. \& Szucsich N.U. 2005: Mouthparts of flower-visiting insects. Arthr. Struct. Devel. 34: 1-40.

Mansell M.W. 1977: A new genus and species in the Crocinae (Neuroptera: Nemopteridae) from southern Africa. J. Entomol. Soc. Sth Afr. 40: 195-203.

Mansell M.W. 1980: The Crocinae of southern Africa (Neuroptera: Nemopteridae). 1. The genera Laurhervasia Navas and
Thysanocroce Withycombe. J. Entomol. Soc. Sth Afr. 43: 341-365.

Mansell M.W. 1983: New Crocinae (Neuroptera: Nemopteridae) from South America, with descriptions of larvae. $J$. Entomol. Soc. Sth Afr. 46: 115-130.

Mansell M.W. 1986: Biogeography and phylogeny of the Crocinae (Neuroptera: Nemopteridae). In Gepp J., Aspöck H. \& Hölzel H. (eds): Recent Research in Neuropterology. Thalerhof, Graz, pp. 77-85.

Mansell M.W. 1992: The systematic position of Nemopteridae (Insecta: Neuroptera: Myrmeleontoidea). In Canard M., Aspöck H. \& Mansell M.W. (eds): Current Research in Neuropterology. SACCO, Toulouse, pp. 233-241.

Mansell M.W. 1996: Unique morphological and biological attributes: the keys to success in Nemopteridae (Insecta: Neuroptera). In Canard M., Aspöck H. \& Mansell M.W. (eds): Pure and Applied Research in Neuropterology. SACCO, Toulouse, pp. 171-180.

MonserRat V.J. 1983: Pterocroce capillaris (Klug, 1836) en Europa (Neur., Plan., Nemopteridae). Neuroptera Intern. 2: 109-128.

MonserRat V.J. 1985: Nuevos datos sobre los Myrmeleontoidea ibéricos (Neur., Plan., Myrmeleonidae, Ascalaphidae, Nemopteridae). Bol. Soc. Portug. Entomol. 2 (Supl. 1): 475-489.

MonserRat V.J. 1996: Larval stages of European Nemopterinae, with systematic considerations on the family Nemopteridae (Insecta, Neuroptera). Dt. Entomol. Z. 43: 99-121.

Monserrat V.J. \& Martinez M.D. 1995: On the possible myrmecophily of Nemopterinae larvae (Neuroptera, Nemopteridae). Sociobiology 26: 55-68.

NEw T.R. 1989: Planipennia. Lacewings. In Fischer M. (ed.). Handbook of Zoology. Vol. IV. Arthropoda: Insecta. Part 30. Walter de Gruyter, Berlin, New York, xi + 132 pp.

Pernstich A., Krenn H.W. \& Pass G. 2003: Preparation of serial sections of arthropods using 2,2-dimethoxypropane dehydration and epoxy resin embedding under vacuum. Biotech. Histochem. 78: 1-5.

Picker M.D. 1984: A new genus and species of spoon-wing lacewing (Neuroptera: Nemopteridae) from Namaqualand, South Africa. J. Entomol. Soc. Sth Afr. 47: 259-268.

PICKER M.D. 1987: An unusual species of spoon-wing lacewing (Neuroptera: Nemopteridae) from South Africa, with notes on its biology. Syst. Entomol. 12: 239-248.

Picker M.D. \& LEON B. 1990: Population biology of Palmipenna aeoleoptera Picker with reference to the possible semaphore function of the hindwings (Insecta: Neuroptera: Nemopteridae). In Mansell M.W. \& Aspöck H. (eds): Advances in Neuropterology. Department of Agricultural Development, Pretoria, pp. 95-99.

Popov A. 1963: An interesting lacewing insect in Bulgaria, Nemoptera sinuata. Priroda (Sofia) 12(3): 90-93 [in Bulgarian].

Popov A. 1967: Investigations on the Ecology, Biology and Distribution of Nemoptera sinuata Oliv. (Insecta, Neuroptera). St. Kliment Ohridski University of Sofia, Biological Faculty, Sofia, 143 pp. [in Bulgarian].

Popov A. 1971: Verbreitung der europäischen NemopteridenArten (Neuroptera). Bull. Inst. Zool. Mus. 32[1970]: 5-31 [in Bulgarian, German and Russian abstr.].

Popov A. 1973: Über die präimaginalen Stadien paläarktischer Vertreter der Ordnung Neuroptera und Versuch einer neuen systematischen Gruppierung der Familien mit Rücksicht auf ihre morphologischen und ökologischen Besonderheiten. Bull. Inst. Zool. Mus. 37: 79-101. 
Popov A. 1998: Bionomy and development of Nemoptera sinuata Olivier (Neuroptera, Nemopteridae). Acta Zool. Fenn. 209: 215-216.

Popov A. 2002: Autecology and biology of Nemoptera sinuata Olivier (Neuroptera: Nemopteridae). Acta Zool. Acad. Sci. Hung. 48 (Suppl. 2): 293-299.

Popov A. 2007: Distribution of the families of Neuroptera with low species diversity in Bulgaria. Ann. Mus. Civ. Stor. Nat. Ferrara 8[2005]: 117-130.

Simpson M.G. 2006: Plant Systematics. Elsevier, Amsterdam, xi $+590 \mathrm{pp}$

Snodgrass R.E. 1935. Principles of Insect Morphology. McGraw-Hill, New York, ix + 667 pp.

Tillyard R.J. 1926: The Insects of Australia and New Zealand. Angus and Robertson, Sydney, 560 pp.

TJEDER B. 1958: On the insect fauna of Cyprus. Results of the expedition of 1939 by Harald, Håkan and P.H. Lindberg. XI. Neuroptera, collected in Cyprus by Dr. Håkan Lindberg. 1. Fam. Nemopteridae. Comment. Biol. 10 (6): 9 pp
TJeder B. 1967: Neuroptera - Planipennia. The Lace-wings of Southern Africa. 6. Family Nemopteridae. Sth Afr. Anim. Life 13: $290-501$.

TJEDER B. 1974: Nemopteridae from the Island of Socotra (Neuroptera) with descriptions of two genera. Entomol. Scand. 5: 291-299.

Villenave J., Thierry D., Mamun A.A., Lodé T. \& Rat-Morris E. 2005: The pollens consumed by common green lacewings Chrysoperla spp. (Neuroptera: Chrysopidae) in cabbage crop environment in western France. Eur. J. Entomol. 102: 547-552.

WeBer H. 1933: Lehrbuch der Entomologie. Gustav Fischer, Stuttgart, xii +726 pp.

Withycombe C.L. 1925: Some aspects of the biology and morphology of the Neuroptera. With special reference to the immature stages and their possible phylogenetic significance. Trans. Entomol. Soc. Lond. 1923: 303-411.

Received August 20, 2007; revised and accepted November 7, 2007 